\title{
Ajude o Math: Um game para o auxílio no estudo da matemática
}

\author{
Marçal J.O. Morais II ${ }^{1}$, Ricardo A. S. Sena ${ }^{1}$, Auany L. F. da Silva ${ }^{1}$ \\ ${ }^{1}$ Instituto Federal de Educação, Ciência e Tecnologia do Rio Grande do Norte (IFRN) - \\ Campus Avançado de Parelhas \\ R. Dr. Mauro Duarte, s/n, - José Clovis, Parelhas - RN, 59360-000 \\ marcal.morais@ifrn.edu.br, \{ricardoadley, auany.lidia\}@gmail.com
}

\begin{abstract}
This article describes the process of elaboration and development of the game Help the Math that has, as a purpose, the insertion of ICT in the classroom contributing to the teaching and study of the basic operations of mathematics in a playful way. It is hoped that the end of development and application of the game will bring about that the expected results will be achieved and that this new means of transmitting teachings will be well accepted by students and teachers.
\end{abstract}

Resumo. Este artigo descreve o processo de elaboração e desenvolvimento do jogo Ajude o Math que possui, como finalidade, a inserção das TIC's na sala de aula contribuindo para o ensinamento e estudo das operações básicas da matemática de forma lúdica. Espera-se ao fim do desenvolvimento e aplicação do jogo que os resultados esperados sejam alcançados e que esse novo meio de transmitir ensinamentos seja bem aceito por alunos e professores.

\section{Introdução}

Com o avanço da tecnologia, novas formas para um ensinamento vêm surgindo impulsionadas pelo uso das TIC's devendo esse potencial ser altamente explorado nas salas de aula. Como diz Madeira (2017) a área da Educação, ao acompanhar as mudanças e evoluções tecnológicas, deveria usar as Tecnologias da Informação e Comunicação (TIC) para proporcionar, nesse sentido, um enriquecimento dos ambientes de ensino e de aprendizagem, oportunizando, assim, espaços de convivência e, consequentemente, espaços de inovações.

Ao observamos a didática adotada pelo uso das TIC's, podemos notar que os jogos digitais se tornam uma peça fundamental para a aplicação na sala de aula, pois, como diz Silvera et al. (2012) os jogos educativos baseiam-se tanto no interesse que as crianças têm em brincar quanto no de jogar e, sendo assim, eles criam ambientes de aprendizagem atraente e lúdica, constituindo-se num recurso poderoso de estímulo para o desenvolvimento integral do aluno.

Sendo uma junção desses dois fatores, os jogos computacionais despertam o interesse das crianças, por permitir a possibilidade de jogar ao enfrentar desafios como também brincar ao seguir o enredo do jogo. 
Ao notarmos o potencial apresentado pelos jogos digitais em sala de aula, demos início ao desenvolvimento do jogo "Ajude o Math" com o intuito de tornar o estudo da matemática mais atrativo para os alunos e junto a isso, a possibilidade de praticar, o lecionado na escola, de forma lúdica e divertida em casa.

\section{Metodologia}

\subsection{Plataforma de desenvolvimento}

A plataforma de desenvolvimento adotada para a criação do jogo foi o Construct 2 (figura 1), uma aplicação que permite o desenvolvimento de jogos 2D baseados em HTML5 e sem exigências previas de conhecimentos em programação já que utiliza a metodologia "drag and drop" (pegar e largar) não exigindo, assim, a digitação de nenhuma linha de código.

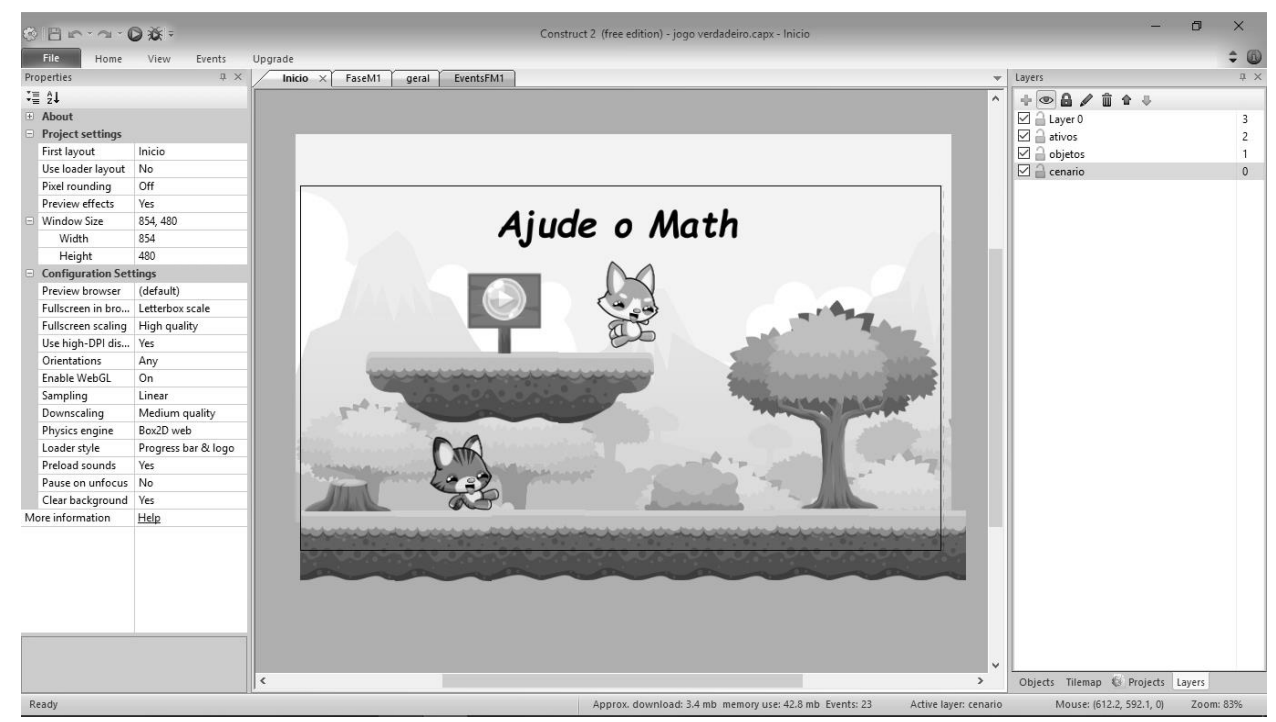

Figura 1.Interface da aplicação Construct 2 no desenvolvimento da página inicial do jogo. Fonte: Acervo pessoal.

\subsection{Jogabilidade}

Seguindo a modalidade de jogo em plataforma, ajude o Math, tem como finalidade atrair os estudantes com uma interface divertida tendo em suas fases como principal desafio operações básicas da matemática (multiplicação, divisão, adição e subtração).

Como destaca Silveira et al. (2012), os jogos educativos digitais têm em sua elaboração o intuito de divertir os alunos e aumentar a chance na aprendizagem de conceitos, conteúdos e habilidades embutidas no jogo. Um jogo educativo computadorizado pode propiciar ao aluno um ambiente de aprendizagem rico e complexo.

Com isso em mente, as fases do jogo foram desenvolvidas de modo que a diversão não fosse deixada de lado enquanto os ensinamentos a serem transmitidos encontram-se embutidos nos jogos por meio de caixas desafios como pode ser notado no protótipo da fase inicial (figura 2). 


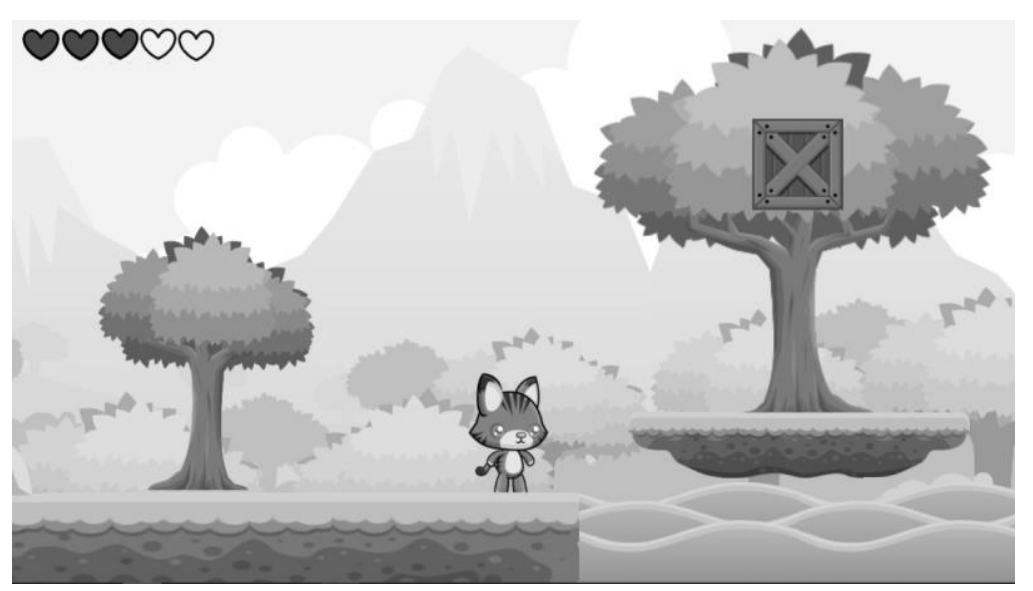

Figura 2. Protótipo da fase inicial do jogo Ajude o Math onde pode-se notar uma caixa desafio e um dos personagens. Fonte: Acervo Pessoal.

\subsection{Personagens}

Com a finalidade de tornar o jogo o mais atraente possível para os alunos, foram desenvolvidos dois personagens (figura 3). Math, um cachorro e personagem principal no enredo do jogo e Joe, um gato e personagem secundário no jogo. Sendo possível pelo jogador a escolha de qual personagem lhe agrada mais.
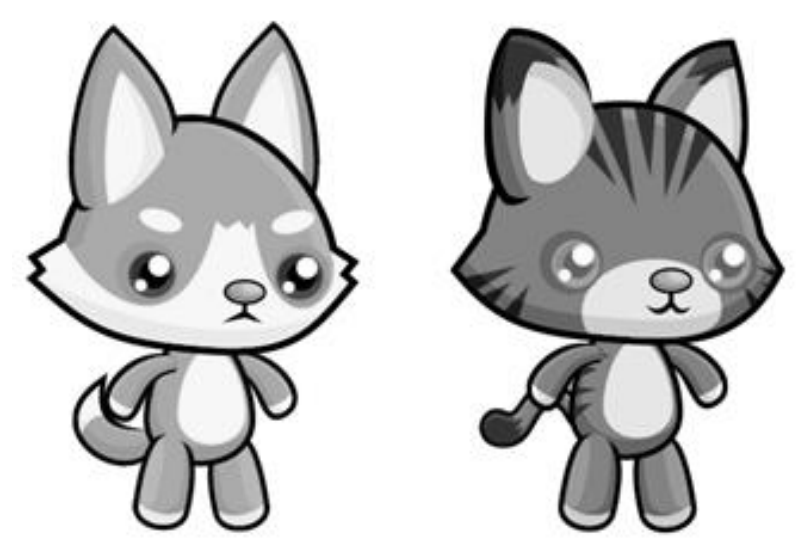

Figura 3. Personagens do jogo Math, o cachorro e Joe, o gato. Fonte: Acervo Pessoal.

\section{Resultados esperados}

Espera-se, com a aplicação do jogo, que interesse dos alunos pela matemática, juntamente com a capacidade de absorção de conhecimento pelos mesmos, seja expandida. Juntamente a isso, espera-se que a metodologia do uso de jogos no ensino seja bem recebida tanto por alunos quanto por professores.

Como afirma Silveira et al. (2012) os resultados fornecidos pelos jogos podem ser os não previstos em sua elaboração, e mesmo assim serão tão importantes quanto os previamente determinados. Podem oferecer oportunidades para o aluno usar lógicas, raciocínio e habilidades de organização para resolver problemas de maneira mais interessante do que seriam expostos em um exercício comum. 


\section{Considerações finais}

Com o jogo ainda em fase de protótipo, e em constante mudança durante seu desenvolvimento espera-se, ao finalizar o produto, que os resultados almejados sejam alcançados, bem como, a aplicação seja bem-sucedida, a fim de possibilitar a aplicação em outras áreas e, futuramente, o desenvolvimento de novos jogos com a finalidade de inserir as TIC's cada vez mais no espaço escolar e, com isso, permitir um ensino mais lúdico para os alunos.

\section{Referências}

Madeira, C. (2017) Introdução ao Pensamento Computacional com Scratch. In Anais do II Congresso sobre Tecnologias na Educação (CTRL+E-2017), p. 725-730.

Silveira, S. R., Rangel, A.C.S., Ciríaco, E.L.(2012) Utilização de Jogos Digitais Para o Desenvolvimento do Raciocínio Lógico-Matemático. In Revista de Educação Ciência e Tecnologia (\#TEAR), v.1, n.1, Canoas. 